\title{
Leukotrienes as Mediators in Ischemia-Reperfusion Injury in a Microcirculation Model in the Hamster
}

\author{
H. A. Lehr, ${ }^{\star}$ A. Guhimann, ${ }^{\circ}$ D. Nolte, ${ }^{\star}$ D. Keppler, ${ }^{\ddagger}$ K. Messmer \\ ${ }^{*}$ Department of Experimental Surgery, University of Heidelberg, 6900 Heidelberg, Germany; ${ }^{\ddagger}$ Division of Tumor Biochemistry, German \\ Cancer Research Center, 6900 Heidelberg, Germany; 8 Institute for Surgical Research, University of Munich, 8000 Munich, Germany
}

\begin{abstract}
Leukotriene (LT)B 4 promotes leukocyte chemotaxis and adhesion to the endothelium of postcapillary venules. The cysteinyl leukotrienes, $\mathrm{LTC}_{4}, \mathrm{LTD}_{4}$, and $\mathrm{LTE}_{\mathbf{4}}$, elicit macromolecular leakage from this vessel segment. Both leukocyte adhesion to the endothelium and macromolecular leakage from postcapillary venules hallmark the microcirculatory failure after ischemia-reperfusion, suggesting a role of leukotrienes as mediators of ischemia-reperfusion injury.

Using the dorsal skinfold chamber model for intravital fluorescence microscopy of the microcirculation in striated muscle in awake hamsters and sequential RP-HPLC and RIA for leukotrienes, we demonstrate in this study that $(a)$ the leukotrienes (LT)B $B_{4}$ and LTD 4 elicit leukocyte/endothelium interaction and macromolecular leakage from postcapillary venules, respectively, that $(b)$ leukotrienes accumulate in the tissue after ischemia and reperfusion, and that $(c)$ selective inhibition of leukotriene biosynthesis (by MK-886) prevents both postischemic leukotriene accumulation and the microcirculatory changes after ischemia-reperfusion, while blocking of $\mathrm{LTD}_{4} / \mathrm{E}_{4}$ receptors (by MK-571) inhibits postischemic macromolecular leakage.

These results demonstrate a key role of leukotrienes in ischemia-reperfusion injury in striated muscle in vivo. (J. Clin. Invest. 1991. 87:2036-2041.) Key words: intravital fluorescence microscopy • microcirculation • striated muscle • leukocyte/endothelium interaction • macromolecular leakage
\end{abstract}

\section{Introduction}

Reperfusion injury after focal ischemia to organs and skeletal muscle has been implicated in the development of multi-organ failure and death after primarily successful resuscitation from multiple injury and shock (1). Chemotactic accumulation, activation, and adherence of circulating leukocytes to the endothelium of postcapillary venules hallmark the microcirculatory manifestations of ischemia-reperfusion injury (2-7). Enhanced leukocyte aggregation and altered viscoelastic properties of activated leukocytes favor microvascular obstruction $(3,5)$. Toxic oxygen radicals and degranulation products like hydro-

Address correspondence and reprint requests to Dr. Hans-Anton Lehr, Institute for Surgical Research, University of Munich, Marchioninistrasse 15, D-8000 Munich 70, Germany.

Received for publication 28 September 1990 and in revised form 19 December 1990

J. Clin. Invest.

(C) The American Society for Clinical Investigation, Inc.

0021-9738/91/06/2036/06\$2.00

Volume 87, June 1991, 2036-2041 lytic enzymes contribute to the full manifestation of ischemiareperfusion injury (8-11), characterized by the breakdown of capillary perfusion and the loss of endothelial integrity $(2,5,12)$.

Leukotrienes, metabolites of arachidonate produced in the 5-lipoxygenase pathway, initiate many of the symptoms associated with ischemia-reperfusion injury. The cysteinyl leukotrienes (LT), ${ }^{1} \mathrm{LTC}_{4}, \mathrm{LTD}_{4}$, and $\mathrm{LTE}_{4}$, affect the tonus of the arterioles and the permeability of postcapillary venules, thereby causing endothelial contraction and macromolecular leakage (13-16). The dihydroxylated $\mathrm{LTB}_{4}$, one of the most powerful chemotactic substances known, has been implicated in the process of leukocyte accumulation, adhesion to the microvascular endothelium, emigration from the blood stream at sites of inflammation $(13,17-19)$, degranulation, and release of lysosomal enzymes (20-22) as well as generation of oxygen radicals $(22,23)$.

There is evidence that leukotrienes, in particular $\mathrm{LTB}_{4}$, enhance leukocyte adhesion to the endothelium by a mechanism dependent on the expression of the CD11/CD18 (Mac-1) glycoprotein family $(24)$ on the leukocyte surface $(25,26)$. Monoclonal antibodies, which bind to the CD18 glycoprotein portion of the leukocyte adhesion receptors, were reported to inhibit $\mathrm{LTB}_{4}$-induced chemotaxis, adhesion of leukocytes to the endothelium, and macromolecular leakage $(11,26-28)$ and thus alleviate ischemia-reperfusion injury $(29,30)$.

The concept that leukotrienes are involved in ischemia-reperfusion injury has furthermore been supported by reports of enhanced generation of 5-lipoxygenase products in postischemic organs (31-34). The recent demonstration of enhanced leukotriene levels in venous effluent from hindlimbs after experimental ischemia and reperfusion (35) suggests that similar mechanisms exist in striated skeletal muscle.

It was the aim of this study to investigate the mediator role of leukotrienes in the pathogenesis of ischemia-reperfusion injury in striated muscle. Using the dorsal skinfold chamber model in hamsters (36) for intravital microscopy of the microcirculation of striated muscle, we demonstrate in this report that leukotrienes elicit the same pattern of microcirculatory changes as ischemia-reperfusion injury and that the postischemic microcirculatory failure can be effectively prevented by the inhibition of leukotriene generation or leukotriene receptors, suggesting the key role of leukotrienes in ischemia-reperfusion injury in the striated muscle in vivo.

\section{Methods}

Animal model. For intravital fluorescence microscopy, we used the dorsal skinfold chamber preparation in awake Syrian golden hamsters (36). This model permits the microscopic quantification of leukocyte/

1. Abbreviations used in this paper: LT, leukotriene. 
endothelium interaction, macromolecular leakage, and the microhemodynamic parameters vessel diameter and red cell velocity in postcapillary venules of a thin striated muscle contained within the observation window.

Operative technique. The experimental preparation used in this study is similar, except for minor modifications, to that described previously in detail (36). Briefly, Syrian golden hamsters (6-8 wk old, weighing $60-80 \mathrm{~g}$ ) were anesthetized by intraperitoneal injection of pentobarbital $(60 \mathrm{mg} / \mathrm{kg}$ body weight; Nembutal, Abbott, Wiesbaden, Germany). The entire back of the animals was shaven and two titanium frames were implanted so as to sandwich the extended double layer of the skin. One layer was completely removed in a circular area of $15 \mathrm{~mm}$ in diameter and the remaining layer, consisting of epidermis, subcutaneous tissue, and a thin striated skin muscle was covered with a cover slip incorporated in one of the frames. Fine polyethylene catheters ([PE] 10, inner diameter $0.28 \mathrm{~mm}$ ) were inserted into the jugular vein and the carotic artery, respectively, passed subcutaneously to the dorsal side of the neck, and sutured to the titanium frames. The animals tolerated the dorsal skinfold chambers well and showed no signs of discomfort. In particular, no effect on sleeping and feeding habits were observed.

Intravital fluorescence microscopy. A recovery period of 48-72 h between implantation of the observation chamber and the microscopic investigation was allowed to eliminate the effects of anesthesia and surgical trauma on the microvasculature. A 4-h ischemia was induced to the chamber tissue by gently pressing the muscle against the cover slip with a silicone pad and an adjustable screw, just sufficient to empty the blood vessels (6). A 25 -fold water immersion objective (total magnification 560-fold; E. Leitz, Inc., Wetzlar, Germany) was used to select four to six sites of interest per chamber, each containing one or several postcapillary venules or collecting venules (10-60 $\mu \mathrm{m}$ in diameter). These vessel segments were chosen for investigation, because they are considered the major site of interaction between leukocytes and the endothelium in response to noxious stimuli (37). By means of a computer-controlled stepping motor (38) the identical vessel segments were investigated for leukocyte/endothelium interaction, diameter, and red cell velocity before ischemia and at all times after reperfusion. For visualization of leukocytes, the in vivo fluorescent marker acridine orange (Sigma Chemical Co., St. Louis, MO) was infused intravenously at a constant rate of $0.5 \mathrm{mg} \mathrm{kg}^{-1} \mathrm{~min}^{-1}$ for a maximum microscopic recording of 4-6 min. Epiillumination was achieved with a $75 \mathrm{~W}, \mathrm{DC}$, xenon lamp attached to a Ploemopak illuminator (E. Leitz, Inc.) with a $\mathrm{I}_{2}$ blue filter block. The microscopic images (Camera COHU 4400; Prospective Measurements, San Diego, CA) were recorded on video tape and analyzed during playback using the computer-assisted Microcirculation Analysis System (CAMAS) (38). Adhesive leukocytes were defined as cells that did not move or detach from the endothelial lining within the observation time of $1 \mathrm{~min}$ and are given as number of cells per $\mathrm{mm}^{2}$ of endothelial surface as calculated from diameter and length of the vessel segment studied $(200 \mu \mathrm{m})$. Macromolecular leakage was assessed by intravenous injection of FITC-conjugated dextran $\left(M_{r}\right.$ $150,000,5 \mathrm{mg}$ in $100 \mu 1$ saline; Pharmacia Fine Chemicals, Uppsala, Sweden), intravital microscopy (total magnification 40-fold), and planimetric quantification of the area where the fluorescent marker had extravasated into the interstitial space, given as a percentage of the observation field (38).

Topical leukotriene application. In order to assess the direct microcirculatory effects of topical leukotriene administration, the leukotrienes $\mathrm{LTB}_{4}$, $\mathrm{LTD}_{\mathbf{4}}$, (Amersham Buchler, Braunschweig, Germany), and the vehicle ( $1 \%$ ethanol in $0.9 \%$ saline) were superfused for a period of $3 \mathrm{~min}$ directly onto the striated muscle within the observation window at a concentration of 20 and $5 \mathrm{nM}$, respectively. The superfusates were then washed away with physiological saline and leukocyte/endothelium interaction, vessel diameters, and red cell velocities were assessed in the follow-up period of $20 \mathrm{~min}$ by intravital fluorescence microscopy.

Inhibition of leukotriene synthesis and action. The selective inhibitor of 5-lipoxygenase activation MK-886 (3-[1-(4-chlorobenzyl)-3-t- butyl-thio-5-isopropylindol-2-yl]-2,2-dimethylpropanoic acid) (39) was administered intravenously as a bolus of $20 \mu \mathrm{mol} / \mathrm{kg} 15 \mathrm{~min}$ before induction of ischemia and continued until $2 \mathrm{~h}$ after reperfusion at a

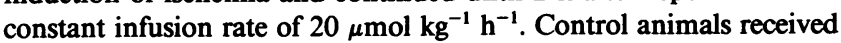
equal volumes of vehicle: $1 \%$ hamster albumin (Sigma Chemical Co.) and $0.9 \%$ benzyl alcohol in $0.9 \%$ saline, $\mathrm{pH} 7.5$.

The selective $\mathrm{LTD}_{4} / \mathrm{E}_{4}$ receptor antagonist MK-571 ((3--(3-(2--(7chloro-2-quinolinyl)ethenyl)phenyl) ((3-(dimethylamino-3-oxopropyl)thio)methyl)thio)propanoic acid) (40) was administered intravenously as a bolus of $2 \mu \mathrm{mol} / \mathrm{kg} 15 \mathrm{~min}$ before induction of ischemia and continued until $2 \mathrm{~h}$ after reperfusion at a constant infusion rate of 2 $\mu \mathrm{mol} \mathrm{kg}{ }^{-1} \mathbf{h}^{-1}$. Control animals received equal volumes of vehicle (0.9\% saline).

Leukotriene analysis. The tissue content of $\mathrm{LTB}_{4}$ and of cysteinyl leukotrienes in nonischemic control and ischemic tissue $0.5 \mathrm{~h}$ after reperfusion was analyzed by the combined use of RP-HPLC and RIA (41-43). Measurements were performed on animals treated with MK886 or equivalent volumes of vehicle. Samples were taken from anesthetized hamsters by freezing of the tissue contained within the postischemic observation window in liquid nitrogen. Reference samples were taken from nonischemic tissue next to the observation chamber in the same animal. The tissue was homogenized at $4^{\circ} \mathrm{C}$ in $80 \%$ (vol/vol) aqueous methanol containing $1 \mathrm{mM}$ 4-hydroxy-2,2,6,6-tetramethylpiperidine- $N$ (1)-oxyl (HTMP; Sigma Chemical Co.) and $0.5 \mathrm{mM}$ EDTA, pH 7.4, spiked with $800 \mathrm{cpm}$ each of $\left[{ }^{3} \mathrm{H}\right] \mathrm{LTB}_{4},\left[{ }^{3} \mathrm{H}\right] \mathrm{LTC}_{4},\left[{ }^{3} \mathrm{H}\right] \mathrm{LTD}_{4}$, and $\left[{ }^{3} \mathrm{H}_{\mathrm{LTE}}\right.$ (New England Nuclear, Boston, MA) to correct for recovery losses in the analysis of endogenous leukotrienes, and stored for at least $3 \mathrm{~h}$ at $-20^{\circ} \mathrm{C}$ under argon. After centrifugation $(10,000 \mathrm{~g}, 10$ $\min , 4^{\circ} \mathrm{C}$ ), aliquots of the supernatants were dried under vacuum (SpeedVac concentrator; Savant Instruments Inc., Hicksville, NY) and resuspended in $30 \%$ (vol/vol) aqueous methanol. Reversed-phase HPLC was performed isocratically on a C18-Hypersil column (4.6 $\times 250 \mathrm{~mm}, 5 \mu \mathrm{m}$ particles; Shandon, Runcorn, England) with a C18 precolumn (Waters Associates, Milford, MA). The mobile phase consisted of $38 \%$ (vol/vol) acetonitrile in aqueous buffer $(0.1 \%$ acetic acid, pH 5.7, adjusted with ammonium hydroxide). The flow rate was $1 \mathrm{ml}$ per min. A 400- $\mu$ laliquot of each $1-\mathrm{ml}$ fraction collected during HPLC was counted for calculation of tritium recovery, and $600 \mu \mathrm{l}$ were dried for the subsequent RIA. The amount of immunoreactive leukotriene metabolites coeluting with the $\left[{ }^{3} \mathrm{H}\right]$ leukotriene standards added to each sample before HPLC were corrected for recovery losses and immunological cross-reactivity in the RIA. The LTB $_{4}$ RIA was performed according to the procedure provided by Amersham Buchler. Instead of the charcoal separation system a scintillation proximity assay (protein A) was used. The molar crossreactivities of the $\mathrm{LTB}_{4}$ antibody at $50 \%$ binding were: $\mathrm{LTB}_{4}, 100 \% ; 20-\mathrm{OH}-\mathrm{LTB}_{4}, 0.4 \%$; 6-trans-LTB $\mathrm{LT}_{4}, 0.4 \%$; other eicosanoids, $<0.05 \%$. The RIA for cysteinyl leukotrienes was performed as previously described (43).

Statistical analysis. The Wilcoxon test with Bonferroni correction was used for calculating $P$ values. $P$ values of $<0.05$ and $<0.01$ were considered significant and are denoted in the figures with one or two asterisks, respectively. Data are given in the figures as mean \pm SD and in the table as mean \pm SEM.

\section{Results}

Microcirculatory changes after ischemia and reperfusion. While under normal conditions, represented by the preischemic baseline situation, the majority of leukocytes passing postcapillary venules and collecting venules did not interact with the endothelial surface, ischemia-reperfusion elicited leukocyte adhesion to the microvascular endothelium with a maximum $0.5 \mathrm{~h}$ after reperfusion (Figs. 1 and $2 A$ ). This phenomenon was seen in all venules ranging from diameters of 10 to $60 \mu \mathrm{m}$. Postischemic leukocyte/endothelium interaction then gradually declined until $24 \mathrm{~h}$ after reperfusion (Fig. $2 \mathrm{~A}$ ). Likewise, 

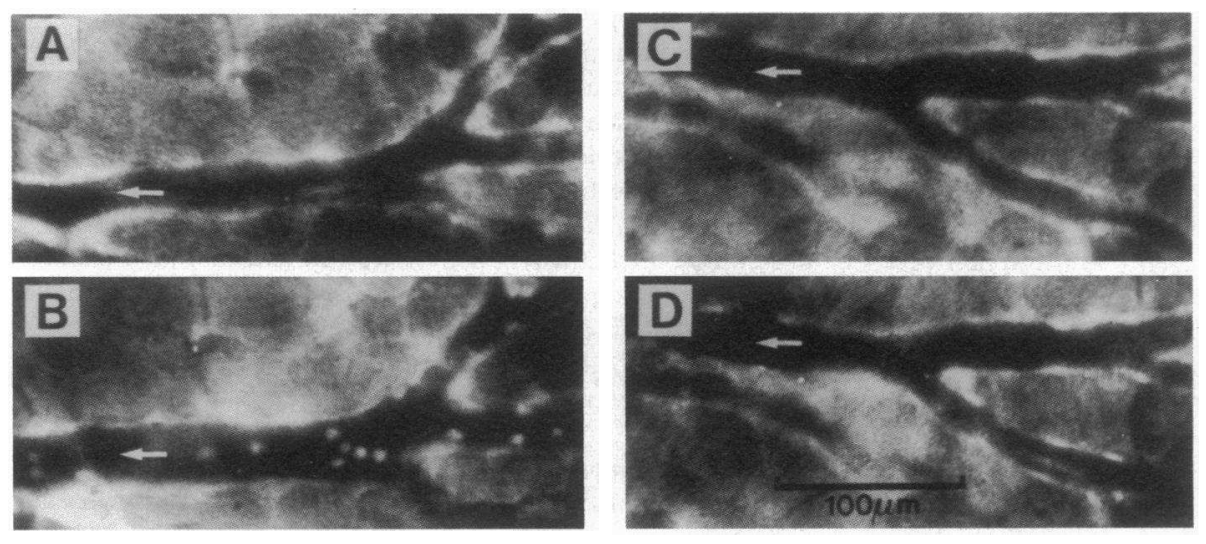

Figure 1. Postcapillary venules of the striated muscle contained within the observation window of a dorsal skinfold chamber in an awake hamster. Venules before induction of ischemia $(A$ and $C)$ and $0.5 \mathrm{~h}$ after reperfusion in control animals $(B)$ and animals treated with the leukotriene biosynthesis inhibitor MK$886(D)$. White dots represent leukocytes stained in vivo with the fluorescent marker acridine orange. Arrows indicate the direction of blood flow. macromolecular leakage from postcapillary venules was observed at 0.5 and $2 \mathrm{~h}$ after reperfusion (Fig. $3 A$ ). No 24-h values could be obtained for macromolecular leakage because of the highly fluorescent background from preceding investigations.

Postischemic leukotriene accumulation. We analyzed the content of 5-lipoxygenase products in the postischemic striated muscle within the observation window after deep-freezing by sequential RP-HPLC and RIA (41-43). The contents of LTB $_{4}$ and cysteinyl leukotrienes were significantly increased in postischemic tissues $0.5 \mathrm{~h}$ after reperfusion as compared with nonischemic control tissue (Table I).

Topical leukotriene application. To test whether topical leukotriene application provoked similar changes in the microcirculation as ischemia-reperfusion, $\mathrm{LTB}_{4}$ and $\mathrm{LTD}_{4}$ were superfused directly onto the striated muscle within the observation window. $\mathrm{LTB}_{4}$ superfusion resulted in an immediate induction of leukocyte adhesion to the endothelium of postcapillary venules and collecting venules, with a maximum at $10 \mathrm{~min}$ after superfusion (Fig. $2 \mathrm{~B}$ ). $\mathrm{LTD}_{4}$ superfusion caused pronounced macromolecular leakage from these microvascular segments (Fig. $3 \mathrm{~B}$ ), the time course of this effect being similar as the induction of leukocyte adhesion after $\mathrm{LTB}_{4}$ challenge. Changes
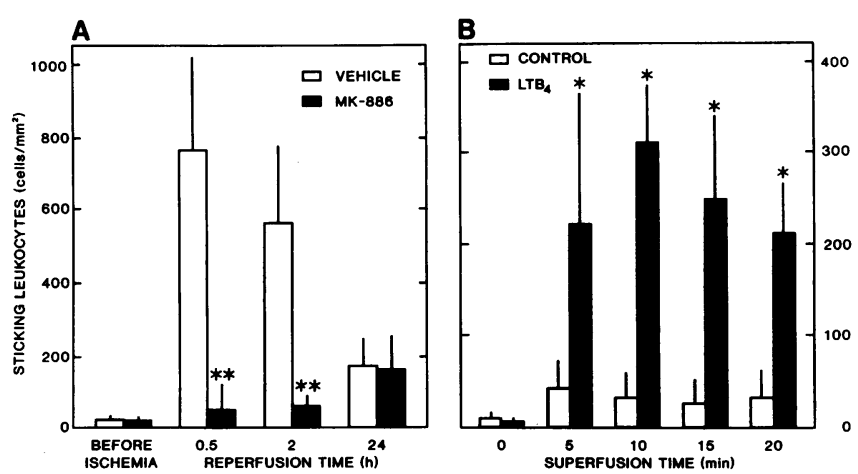

Figure 2. Leukocyte/endothelium interaction after ischemia-reperfusion $(A)$ and topical application of $\mathrm{LTB}_{4}(B)$. Sticking leukocytes are expressed as number per $\mathrm{mm}^{2}$ of endothelial surface. $(A)$ Measurements of postischemic leukocyte/endothelium interaction were performed on animals treated with MK-886 $(n=7)$ or vehicle $(n=7)$. (B) $\mathrm{LTB}_{4}(20 \mathrm{nM})$ or vehicle were superfused onto the striated muscle within the observation chambers in five animals per group.

Each column represents measurements of 36-47 investigated vessels. Data are the mean \pm SD. ${ }^{*} P<0.05$ and ${ }^{* *} P<0.01$, as compared with corresponding values in vehicle-treated animals. of red blood cell velocity and vessel diameter were not observed after leukotriene application. Superfusion with the vehicle had no effect on leukocyte/endothelium interaction, macromolecular leakage, or microhemodynamic parameters, suggesting that neither the vehicle nor the experimental condition imposed any artefacts on these assessments.

Inhibition of leukotriene biosynthesis. In order to demonstrate the essential role of leukotrienes in ischemia-reperfusion injury of striated muscle, leukotriene biosynthesis was pharmacologically inhibited by MK-886, which selectively blocks 5-lipoxygenase activation in vitro $(39)$ and in vivo $(39,43)$. Effective plasma levels of MK-886 were ascertained at various times by the measurement of $\mathrm{LTB}_{4}$ generation in whole blood after ex vivo stimulation with the calcium ionophore $A 23187$ according to Tateson et al. (44). The applied dose of MK-886 did not induce changes in blood pressure and heart rate. After $4 \mathrm{~h}$ of ischemia and $0.5 \mathrm{~h}$ of reperfusion, the accumulation of $\mathrm{LTB}_{4}, \mathrm{LTD}_{4}, \mathrm{LTC}_{4}$, and $\mathrm{LTE}_{4}$ in the postischemic chamber tissue was almost completely suppressed in MK-886-treated animals (Table I). Concomitantly, postischemic leukocyte/endothelium interaction and macromolecular leakage from post-
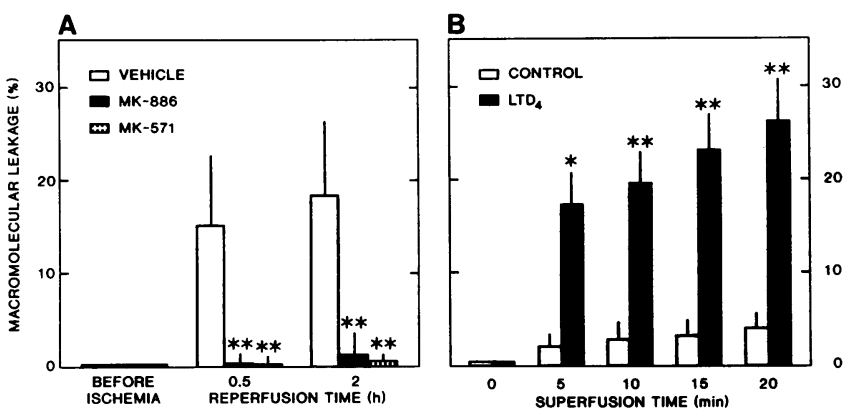

Figure 3. Macromolecular leakage after ischemia-reperfusion $(A)$ and topical application of $\operatorname{LTD}_{4}(B)$. Macromolecular leakage was assessed by planimetric quantification of the area where the fluorescent marker FITC-dextran had extravasated into the interstitial space, given as a percentage of the observation field. $(A)$ Measurements of postischemic macromolecular leakage were performed on animals treated with MK-886 $(n=7)$, MK-571 $(n=6)$, or vehicle. Postischemic leakage was similar in the vehicle controls for MK-886 and for MK-571 (0.9\% saline; $n=6)$. $(B)$ LTD $_{4}(5 \mathrm{nM})$ or vehicle were superfused onto the striated muscle within the observation chamber in five animals per group. Data are the mean \pm SD. ${ }^{*} P<0.05$ and ${ }^{* *} P$ $<0.01$, as compared with corresponding values in vehicle-treated animals. 
Table I. Tissue Content of $\mathrm{LTB}_{4}$ and Cysteinyl Leukotrienes in Nonischemic Control Tissue and in the Postischemic Chamber Tissue 0.5 h after Reperfusion

\begin{tabular}{lrrrrr}
\hline & \multicolumn{2}{c}{ Control } & & \multicolumn{2}{c}{ Reperfusion $(0.5 \mathrm{~h})$} \\
\cline { 2 - 3 } \cline { 5 - 6 } & Vehicle & MK-886 & & Vehicle & MK-886 \\
\hline & \multicolumn{5}{c}{ pmol/g tissue } \\
LTB $_{4}$ & $13.1 \pm 2.9$ & $14.9 \pm 4.2$ & $102.1 \pm 8.4^{*}$ & $22.1 \pm 5.3^{\ddagger}$ \\
LTC $_{4}$ & $0.3 \pm 0.2$ & $1.0 \pm 0.5$ & & $11.5 \pm 2.8^{*}$ & $2.5 \pm 1.6^{\ddagger}$ \\
LTD $_{4}$ & $0.3 \pm 0.2$ & $1.1 \pm 0.8$ & & $11.1 \pm 3.5^{*}$ & $2.2 \pm 1.3^{\ddagger}$ \\
LTE $_{4}$ & $0.4 \pm 0.2$ & $2.1 \pm 1.2$ & & $33.4 \pm 9.2^{*}$ & $2.9 \pm 1.6^{\ddagger}$ \\
SLT $_{\text {CYS }}$ & $1.1 \pm 0.5$ & $4.2 \pm 2.5$ & & $56.1 \pm 13.1^{*}$ & $7.6 \pm 4.4^{\ddagger}$
\end{tabular}

The leukotriene content was analyzed by sequential RP-HPLC and RIA (41-43). Values are given in pmol/g wet weight. Measurements were performed on animals treated with MK-886 $(n=7)$ or vehicle $(n=7)$. $\Sigma$ LT Tys designates total cysteinyl leukotrienes. Data are the mean \pm SEM. ${ }^{*} P<0.001$ as compared with nonischemic tissue, and ${ }^{\ddagger} P<0.01$ as compared with postischemic tissue in vehicle-treated animals.

capillary venules were significantly reduced in MK-886-treated animals (Fig. $2 A$ and $3 A$ ). Differences in postischemic red cell velocities and vessel diameters were not observed between MK-886-treated and control animals (Table II), nor were there differences in systemic blood pressure. Although we cannot rule out changes in perfusion pressure within the observed microvessel segments, these data suggest that the effects of MK886 on the microcirculatory manifestations of ischemia-reperfusion injury were not secondary to microhemodynamic changes or changes in local wall shear force conditions.

Leukotriene receptor antagonist. To further differentiate the effects of $\mathrm{LTB}_{4}$ and of cysteinyl leukotrienes, we administered the selective $\mathrm{LTD}_{4} / \mathrm{E}_{4}$ receptor antagonist MK-571. Postischemic macromolecular leakage from postcapillary venules was entirely prevented by pretreatment with MK-571 (Fig. 3 $A$ ). Under this condition, no reduction was observed of postischemic leukocyte adhesion $30 \mathrm{~min}$ after reperfusion in these

Table II. Microhemodynamic Parameters before Ischemia and after Reperfusion

\begin{tabular}{llll}
\hline & & \multicolumn{1}{c}{ Vehicle } & MK-886 \\
\hline Red cell velocity & Baseline & $0.86 \pm 0.12$ & $0.88 \pm 0.13$ \\
$\mathrm{~mm} / \mathrm{s}$ & $0.5 \mathrm{~h}$ & $0.81 \pm 0.08$ & $0.67 \pm 0.12$ \\
& $2 \mathrm{~h}$ & $0.79 \pm 0.12$ & $0.71 \pm 0.29$ \\
& $24 \mathrm{~h}$ & $0.64 \pm 0.23$ & $0.64 \pm 0.07$ \\
Vessel diameter & Baseline & $30.9 \pm 4.1$ & $32.9 \pm 5.5$ \\
$\mu m$ & $0.5 \mathrm{~h}$ & $36.9 \pm 4.6$ & $38.6 \pm 5.9$ \\
& $2 \mathrm{~h}$ & $38.1 \pm 5.4$ & $41.0 \pm 4.8$ \\
& $24 \mathrm{~h}$ & $40.1 \pm 4.9$ & $42.4 \pm 3.5$ \\
\hline
\end{tabular}

Red cell velocity and vessel diameters were assessed in four to six postcapillary venules per observation chamber before ischemia and in identical vessel segments at defined times after reperfusion. Red cell velocity was assessed by cross-correlation and vessel diameters were assessed planimetrically (38). Data are the mean $\pm \mathrm{SD}$ of $n=7$ animals in the vehicle-treated control group and $n=7$ animals in the MK886-treated group. vessel segments $\left(639 \pm 287\right.$ cells $/ \mathrm{mm}^{2}$ vs. $761 \pm 344$ cells $/ \mathrm{mm}^{2}$ in control animals).

\section{Discussion}

Leukocyte/endothelium interaction and macromolecular leakage from postcapillary venules are characteristic features of ischemia-reperfusion injury. The demonstration that these events can be mimicked by topical application of leukotrienes (Fig. $2 B$ and $3 B$ ) is in accordance with earlier in vitro and in vivo findings in which $\mathrm{LTB}_{4}$ was shown to exert powerful chemotactic activities and promote leukocyte adhesion to and emigration across the endothelial wall of postcapillary venules (13, $17,19)$, whereas the cysteinyl leukotrienes $\mathrm{LTC}_{4}, \mathrm{LTD}_{4}$, and $\mathrm{LTE}_{4}$ were implicated in the regulation of vessel permeability and the induction of macromolecular leakage $(13,14)$.

The concept that leukotrienes are involved in ischemia-reperfusion injury is furthermore supported by the demonstration that leukotrienes accumulate in the postischemic striated muscle $0.5 \mathrm{~h}$ after reperfusion (Table $\mathrm{I}$ ). This finding is in consistence with, and extends, previous reports on increased leukotriene generation in postischemic brain (31), intestine (34), and myocardium (32), as well as elevated leukotriene levels in venous effluent after temporal renal (33) and hindlimb ischemia (35).

When endogenous leukotriene biosynthesis was pharmacologically inhibited by pretreating the animals with the leukotriene biosynthesis inhibitor MK-886, both postischemic leukotriene accumulation and the microcirculatory changes of ischemia-reperfusion injury were entirely prevented (Figs. $2 \mathrm{~A}$ and $3 A$ ). This finding extends previous observations obtained in the same animal model, where postischemic capillary blockade was effectively prevented by pretreatment of the animals with the same leukotriene biosynthesis inhibitor (45), and supports the idea that enhanced leukocyte adhesivity accounts for capillary obstruction after ischemia-reperfusion (7).

The concept that $\mathrm{LTB}_{4}$ accounts for postischemic leukocyte/endothelium interaction, while the cysteinyl leukotrienes mediate macromolecular leakage, is furthermore substantiated by the finding that postischemic macromolecular leakage was effectively prevented by pretreating the animals with the $\mathrm{LTD}_{4} / \mathrm{E}_{4}$ receptor antagonist MK-571 (Fig. $3 \mathrm{~A}$ ). These results emphasize the pivotal role of cysteinyl leukotrienes in the regulation of postischemic vessel permeability $(13,14)$.

MK-886 inhibits leukotriene biosynthesis by blocking the $\mathrm{Ca}^{++}$-dependent translocation of cytosolic 5-lipoxygenase to its membrane-bound activator protein (46-48). In contrast to previously available lipoxygenase inhibitors, which inhibit various lipoxygenases via redox mechanisms $(3,32-34,49)$, MK-886 specifically inhibits the synthesis of 5-lipoxygenase products and exerts no nonspecific antioxidant effects (39). This fact is of particular relevance because oxygen radicals contribute to ischemia-reperfusion injury $(8,10,11)$ and since radical scavengers have been reported to alleviate ischemia-induced leukocyte accumulation $(3,9-11)$ and macromolecular leakage $(2,50)$. Using nonspecific lipoxygenase inhibitors and antioxidants, it could not be decided whether the lipoxygenase inhibitors interfered with oxygen radical formation or, in turn, whether antioxidants interfered with leukotriene generation. Therefore, it was not possible to differentiate the effects of leukotrienes from the effects of oxygen radicals on the microcircu- 
latory manifestation of ischemia-reperfusion injury $(3,32-34$, 49). This problem has recently been addressed in an in vitro study where nonoxidant lipoxygenase inhibitors were demonstrated to be devoid of direct inhibitory effects on leukocytes, supporting the concept that the salvaging effect of these inhibitors in ischemia-reperfusion is due to the inhibition of leukotriene generation (51). Our use of a selective inhibitor of leukotriene biosynthesis, which exerts no nonspecific antioxidant effects (39), together with leukotriene analysis in the postischemic tissue, has now allowed to demonstrate the key role of leukotrienes in ischemia-reperfusion injury in striated muscle. However, it should be considered that, depending on tissue type, animal species, and experimental setting, leukotrienes will be only part of a network of mediators comprising complement factors (52), other eicosanoids such as thromboxane $A_{2}$ (see reference 33 ) and lipid mediators like platelet activating factor (53).

Inhibition of either leukotriene or oxygen radical formation alone prevents postischemic leukocyte adhesion and tissue injury, which suggests that the joint action of both classes of mediators is necessary for the adequate microcirculatory response to ischemia-reperfusion. Because oxygen radical scavengers failed to inhibit leukocyte adhesion to endothelial monolayers in response to chemoattractants like $\mathrm{LTB}_{4}$ and $\mathrm{fMPL}$ (54), Granger et al. (10) have put forward the hypothesis that oxygen radicals, produced at the moment of reperfusion through the action of xanthine oxidase, initialize the formation of further mediators which then activate and promote the adhesion of leukocytes to the microvascular endothelium. The results obtained in this study as well as data from the literature (32) suggest that these adhesion promoting mediators are leukotrienes, in particular $\mathrm{LTB}_{4}$, generated and released from locally activated leukocytes.

Ischemia-reperfusion-induced macromolecular leakage has been found significantly attenuated by the inhibition of leukocyte/endothelium interaction through leukocyte depletion (5, 55) or monoclonal antibodies directed towards leukocyte adhesion molecules (5). These observations indicate that leukocyte adhesion to the endothelium is a critical step in the sequelae leading to ischemia-reperfusion injury and suggest that macromolecular leakage is promoted by substances released from leukocytes after adhesion and degranulation (10). Our observation that pretreatment with the highly selective $\mathrm{LTD}_{4} / \mathrm{E}_{4}$ receptor antagonist MK-571 (Fig. $3 \mathrm{~A}$; reference 40) effectively inhibited macromolecular leakage without affecting leukocyte/endothelium interaction suggests that cysteinyl leukotrienes, generated by adherent leukocytes, are substantially involved in the loss of endothelial integrity.

Taken together, our results suggest that in addition to the role of oxygen free radicals, leukotrienes play a key role in ischemia-reperfusion injury in vivo by mediating both the recruitment and adhesion of leukocytes to the microvascular endothelium and the loss of endothelial integrity.

\section{Acknowledgments}

The excellent technical assistance of Juliane Müller is gratefully acknowledged. MK-886 and MK-571 were kindly provided by Dr. A. W. Ford-Hutchinson, Merck Frosst, Canada.

This study was supported in part by the Deutsche Forschungsgemeinschaft through Sonderforschungsbereich 320 and by the Forschungsschwerpunkt Transplantation, Heidelberg.

\section{References}

1. Messmer, K., U. Kreimeier, and F. Hammersen. 1988. Multiple organ failure: clinical implications to macro- and microcirculation. In Microcirculation in Clinical Disorders. H. Manabe, B. Z. Zweifach, and K. Messmer, editors. Springer-Verlag Tokyo, Japan. 147-157.

2. Korthuis, R. J., D. N. Granger, M. I. Townsley, and A. E. Taylor. 1985. The role of oxygen-derived free radicals in ischemia-induced increases in canine skeletal muscle vascular permeability. Circ. Res. 57:599-609.

3. Mullane, K. M., J. A. Salmon, and R. Kraemer. 1987. Leukocyte-derived metabolites of arachidonic acid in ischemia-induced myocardial injury. Fed. Proc. 46:2422-2433.

4. Hammersen, F., and E. Hammersen. 1987. The ultrastructure of endothelial gap formation and leukocyte emigration. Prog. Appl. Microcirc. 12:1-34.

5. Hernandez, L. A., M. B. Grisham, B. Twohig, K. E. Arfors, J. M. Harlan, and D. N. Granger. 1987. Role of neutrophils in ischemia-reperfusion-induced microvascular injury. Am. J. Physiol. 253:H699-703.

6. Sack, F. U., W. Funk, F. Hammersen, and K. Messmer. 1987. Microvascular injury of skeletal muscle and skin after different methods of pressure induced ischemia. Prog. Appl. Microcirc. 12:282-288.

7. Schmid-Schönbein, G. W. 1987. Capillary plugging by granulocytes and the no-reflow phenomenon in the microcirculation. Fed. Proc. 46:2397-2401.

8. Parks, D. A., G. B. Bulkley, D. N. Granger, S. P. Hamilton, and J. M. McCord. 1982. Ischemic injury in the cat small intestine: role of superoxide radicals. Gastroenterology. 82:9-15.

9. Grisham, M. B., L. A. Hernandez, and D. N. Granger. 1986. Xanthine oxidase and neutrophil infiltration in intestinal ischemia. Am. J. Physiol. 251:G567-G574.

10. Granger, D. N., J. N. Benoit, M. Suzuki, and M. B. Grisham. 1989. Leukocyte adherence to venular endothelium during ischemia-reperfusion. $A m$. J. Physiol. 257:G683-G688.

11. Suzuki, M., W. Inauen, P. R. Kvietys, M. B. Grisham, C. Meininger, M. E. Schelling, H. J. Granger, and D. N. Granger. 1989. Superoxide mediates reperfusion-induced leukocyte-endothelial cell interactions. Am. J. Physiol. 257:H1740H1745.

12. Menger, M. D., F. U. Sack, J. H. Barker, G. Feifel, and K. Messmer. 1988. Quantitative analysis of microcirculatory disorders after prolonged ischemia in skeletal muscle. Res. Exp. Med. 188:151-165.

13. Dahlén, S. E., J. Björk, P. Hedqvist, K. E. Arfors, S. Hammarström, J. A. Lindgren, and B. Samuelsson. 1981. Leukotrienes promote plasma leakage and leukocyte adhesion in postcapillary venules: in vivo effects with relevance to the acute inflammatory response. Proc. Natl. Acad. Sci. USA. 78:3887-3891.

14. Hua, X. Y., S. E. Dahlén, J. M. Lundberg, S. Hammarström, and P. Hedqvist. 1985. Leukotrienes $C_{4}, D_{4}$ and $E_{4}$ cause widespread and extensive plasma extravasation in the guinea pig. Naunyn-Schmiedeberg's Arch. Pharmacol. 330:136-141.

15. Joris, I., G. Majno, E. J. Corey, and R. A. Lewis. 1987. The mechanism of vascular leakage induced by leukotriene $\mathrm{E}_{4}$. Am. J. Pathol. 126:19-24.

16. Leng, W., C. G. Kuo, R. Qureshi, and B. A. Jakschik. 1988. Role of leukotrienes in vascular changes in the rat mesentery and skin in anaphylaxis. $J$. Immunol. 140:2361-2368.

17. Ford-Hutchinson, A. W., M. A. Bray, M. V. Doig, M. E. Shipley, and M. J. H. Smith. 1980. Leukotriene B, a potent chemokinetic and aggregating substance released from polymorphonuclear leukocytes. Nature (Lond.). 286:264-265.

18. Palmblad, J., C. L. Malmsten, A. M. Uden, O. Radmark, L. Engstedt, and B. Samuelsson. 1981. Leukotriene $B_{4}$ is a potent and stereospecific stimulator of neutrophil chemotaxis and adherence. Blood. 58:658-663.

19. Gimbrone, M. A., A. F. Brock, and A. I. Schafer. 1984. Leukotriene B stimulates polymorphonuclear leukocyte adhesion to cultured vascular endothelial cells. J. Clin. Invest. 74:1552-1555.

20. Rae, S. A., and M. J. H. Smith. 1981. The stimulation of lysosomal enzyme secretion from human polymorphonuclear leukocytes by leukotriene $B_{4}$. J. Pharm. Pharmacol. 33:616-617.

21. Feinmark, S. J., J. A. Lindgren, H. E. Claesson, C. Malmsten, and B. Samuelsson. 1981. Stimulation of human leukocyte degranulation by leukotriene $\mathrm{B}_{4}$ and its w-oxidized metabolites. FEBS (Fed. Eur. Biol. Soc.) Lett. 136:141-144. 22. Serhan, C. N., A. Radin, J. E. Smolen, H. Korchak, B. Samuelsson, and G. Weissmann. 1982. Leukotriene $B_{4}$ is a complete secretagogue in human neutrophils: a kinetic analysis. Biochem. Biophys. Res. Commun. 107:1006-1012.

23. Gyllenhammar, H. 1989. Correlation between neutrophil superoxide formation, luminol-augmented chemiluminescence and intracellular $\mathrm{Ca}^{2+}$ levels upon stimulation with leukotriene $B_{4}$, formylpeptide and phorbolester. Scand. J. Clin. Lab. Invest. 49:317-322.

24. Wallis, W. J., D. D. Hickstein, B. R. Schwartz, C. H. June, H. D. Ochs, P. G. Beatty, S. J. Klebanoff, and J, M. Harlan. 1986. Monoclonal antibody-defined functional epitopes on the adhesion-promoting glycoprotein complex (CDw18) of human neutrophils. Blood. 67:1007-1013.

25. Tonnesen, M. G., D. C. Anderson, T. A. Springer, A. Knedler, N. Avdi, 
and P. M. Henson. 1989. Adherence of neutrophils to cultured human microvascular endothelial cells. J. Clin. Invest. 83:637-646.

26. Lindström, P., R. Lerner, J. Palmblad, and M. Patarroyo. 1990. Rapid adhesive responses of endothelial cells and of neutrophils induced by leukotriene $\mathrm{B}_{4}$ are mediated by leukocytic adhesion protein CD18. Scand. J. Immunol. 31:737-744.

27. Arfors, K. E., C. Lundberg, L. Lindbom, K. Lundberg, P. G. Beatty, and J. M. Harlan. 1987. A monoclonal antibody to the membrane glycoprotein complex CD18 inhibits polymorphonuclear leukocyte accumulation and plasma leakage in vivo. Blood. 69:338-340.

28. Nourshargh, S., M. Rampart, P. G. Hellewell, P. J. Jose, J. M. Harlan, A. J. Edwards, and T. J. Williams. 1989. Accumulation of ${ }^{11}$ in-neutrophils in rabbit skin in allergic and non-allergic inflammatory reactions in vivo. $J$. Im munol. 142:3193-3198.

29. Vedder, N. B., R. K. Winn, C. L. Rice, E. Y. Chi, K. E. Arfors, and J. M Harlan. 1988. A monoclonal antibody to the adherence-promoting leukocyte glycoprotein, $\mathrm{CD18}$, reduces organ injury and improves survival from hemorrhagic shock and resuscitation in rabbits. J. Clin. Invest. 81:939-944.

30. Simpson, P. J., R. F. Todd, J. C. Fantone, J. K. Mickelson, J. D. Griffin and B. R. Lucchesi. 1988. Reduction of experimental canine myocardial reperfusion injury by a monoclonal antibody (anti-Mol, anti-CD11b) that inhibits leukocyte adhesion. J. Clin. Invest. 81:624-629.

31. Moskowitz, M. A., K. J. Kiwak, K. Hekimian, and L. Levine. 1984. Synthesis of compounds with properties of leukotrienes $C_{4}$ and $D_{4}$ in gerbil brains after ischemia and reperfusion. Science (Wash. DC). 224:886-888.

32. Sasaki, K., A. Ueno, M. Katori, and R. Kikiwada. 1988. Detection of leukotriene $\mathrm{B}_{4}$ in cardiac tissue and its role in infarct extension through leukocyte migration. Cardiovasc. Res. 22:142-148.

33. Klausner, J. M., I. S. Paterson, G. Goldman, L. Kobzik, C. Rodzen, R. Lawrence, C. R. Valeri, D. Shepro, and H. B. Hechtman. 1989. Postischemic renal injury is mediated by neutrophils and leukotrienes. Am. J. Physiol. 256:F794-F802.

34. Mangino, M. J., C. B. Anderson, M. K. Murphy, E. Brunt, and J. Turk 1989. Mucosal arachidonate metabolism and intestinal ischemia-reperfusion injury. Am. J. Physiol. 257:G299-G307.

35. Goldman, G., R. Welbourn, I. S. Paterson, J. M. Klausner, L. Kobizik C. R. Valeri, D. Shepro, and H. B. Hechtman. 1990. Ischemia-induced neutrophil activation and diapedesis is lipoxygenase dependent. Surgery. 107:428-433.

36. Endrich, B., K. Asaishi, A. Goetz, and K. Messmer. 1980. Technical report-A new chamber technique for microvascular studies in unanesthetized hamsters. Res. Exp. Med. 177:125-134.

37. Grant, L. 1973. The sticking and emigration of white blood cells in inflammation. In The Inflammatory Process. L. Grant, B. W. Zweifach, and R. T. McCluskey, editors. Academic Press, New York. 205-249.

38. Zeintl, H., F. U. Sack, M. Intaglietta, and K. Messmer. 1989. Computer assisted leukocyte velocity measurement in intravital microscopy. Int. J. Microcirc. Clin. Exp. 8:293-302

39. Gillard, J., A. W. Ford-Hutchinson, C. Chan, S. Sharleson, D. Denis, A. Foster, R. Fortin, S. Leger, C. S. McFarlane, H. Morton, H. Piechuta, D. Riendeau, C. A. Rouzer, J. Rokach, and R. Young. 1989. L-663,536 (MK-886) (3-1-(4-chlorobenzyl)-3-t-butyl-thio-5-isopropylindol-2-yl) 2,2-dimethylpropanoic acid), a novel, orally active leukotriene biosynthesis inhibitor. Can. J. Physiol. Pharmacol. 67:456-464.

40. Jones, T. R., R. Zamboni, M. Belley, E. Champion, L. Charette, A. W.
Ford-Hutchinson, R. Frenette, J. Y. Gauthier, S. Leger, P. Masson, C. S. McFarlane, H. Piechuta, J. Rokach, H. Williams, R. N. Young, R. N. Dehaven, and S. S. Pong. 1989. Pharmacology of L-600,711 (MK-571): a novel potent and selective leukotriene $\mathrm{D}_{4}$ receptor antagonist. Can. J. Physiol. Pharmacol. 67:17-28.

41. Denzlinger, C., S. Rapp, W. Hagmann, and D. Keppler. 1985. Leukotrienes as mediators in tissue trauma. Science (Wash. DC). 230:330-332.

42. Denzlinger, C., A. Guhlmann, P. H. Scheuber, D. Wilker, D. K. Hammer, and D. Keppler. 1986. Metabolism and analysis of cysteinyl leukotrienes in the monkey. J. Biol. Chem. 261:15601-15606.

43. Guhlmann, A., A. Keppler, S. Kästner, H. Krieter, U. B. Brückner, K. Messmer, and D. Keppler. 1989. Prevention of endogenous leukotriene production during anaphylaxis in the guinea pig by an inhibitor of leukotriene biosynthesis (MK-886) but not by dexamethasone. J. Exp. Med. 170:1905-1918.

44. Tateson, J. E., R. W. Randall, C. H. Reynolds, W. P. Jackson, P. Bhattacherjee, J. A. Salmon, and L. G. Garland. 1988. Selective inhibition of arachidonate 5-lipoxygenae by novel acetohydroxamic acids: biochemical assessment in vitro and ex vivo. Br. J. Pharmacol. 94:528-539.

45. Lehr, H. A., A. Guhlmann, D. Nolte, D. Keppler, and K. Messmer. 1991. Preservation of postischemic capillary perfusion by selective inhibition of leukotriene biosynthesis. Trans. Proc. 23:833-834.

46. Dixon, R. A. F., R. E. Diehl, E. Opas, E. Rands, P. J. Vickers, J. F. Evans, J. W. Gillard, and D. K. Miller. 1990. Requirement of a 5-lipoxygenase-activating protein for leukotriene synthesis. Nature (Lond.). 343:282-284.

47. Miller, D. K., J. W. Gillard, P. J. Vickers, S. Sadowski, C. Leveille, J. A. Mancini, P. Charleson, R. A. F. Dixon, A. W. Ford-Hutchinson, R. Fortin, J. Y. Gauthier, J. Rodkey, R. Rosen, C. A. Rouzer, I. S. Sigal, C. D. Strader, and J. F. Evans. 1990. Identification and isolation of a membrane protein necessary for leukotriene production. Nature (Lond.). 343:278-281.

48. Rouzer, C. A., A. W. Ford-Hutchinson, H. E. Morton, and J. W. Gillard. 1990. MK-886, a potent and specific leukotriene biosynthesis inhibitor blocks and reverses the membrane association of 5-lipooxygenase in ionophore-challenged leukocytes. J. Biol. Chem. 265:1436-1442.

49. Jolly, S. R., and B. R. Luchesi. 1983. Effect of BW755C in an occlusion-reperfusion model of ischemic myocardial injury. Am. Heart J. 106:8-13.

50. Ley, K., and K. E. Arfors. 1982. Changes in macromolecular permeability by intravascular generation of oxygen-derived free radicals. Microvasc. Res. 24:25-33.

51. Shappell, S. B., A. A. Taylor, H. Hughes, J. R. Mitchell, D. C. Anderson, and C. W. Smith. 1990. Comparison of antioxidant and nonantioxidant lipoxygenase inhibitors on neutrophil function. Implications for pathogenesis of myocardial reperfusion injury. J. Pharmacol. Exp. Ther. 252:531-538.

52. Maroko, R. P., C. B. Carpenter, N. Chiariello, M. C. Fishbein, P. R Radvany, J. D. Knostman, and S. L. Hale. 1978. Reduction by cobra venom factor of myocardial necrosis after coronary artery occlusion. J. Clin. Invest. 61:661-669.

53. Kubes, P., G. Ibbotson, J. Russell, J. L. Wallace, and D. N. Granger. 1990. Role of platelet-activating factor in ischemia/reperfusion-induced leukocyte adherence. Am. J. Physiol. 259:G300-G305.

54. Rosengren, S., J. Björk, and G. Smedegard. 1988. Oxygen radicals are not a prerequisite for neutrophil-mediated increased vascular permeability. $L a b$. In vest. 58:559-564.

55. Björk, J., P. Hedqvist, and K. E. Arfors. 1983. Increase in vascular permeability induced by leukotriene $B_{4}$ and the role of polymorphonuclear leukocytes. Inflammation. 6:189-200. 